\title{
Operações de traçamento de madeira em povoamentos de eucalipto com a presença e ausência de corredores ecológicos: reflexos no rendimento e custos
}

\author{
Wood tracing operations in eucalyptus stands in the presence and \\ absence of ecological corridors: effects on yield and cost
}

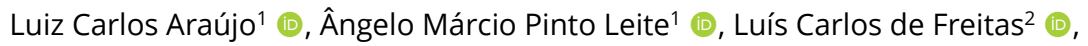 \\ Márcio Leles Romarco de Oliveira' (1) \\ ${ }^{1}$ Universidade Federal dos Vales do Jequitinhonha e Mucuri - UFVJM, Diamantina, MG, Brasil \\ ${ }^{2}$ Universidade Estadual do Sudoeste da Bahia - UESB, Vitória da Conquista, BA, Brasil
}

\begin{abstract}
Como citar: Araújo, L. C., Leite, A. M. P., Freitas, L. C., \& Oliveira, M. L. R. (2021). Operações de traçamento de madeira em povoamentos de eucalipto com a presença e ausência de corredores ecológicos: reflexos no rendimento e custos. Scientia Forestalis, 49(131), e3642. https://doi.org/10.18671/scifor.v49n131.22
\end{abstract}

\begin{abstract}
Resumo
Objetivou-se com esta pesquisa analisar o rendimento operacional da garra traçadora em povoamentos de Eucalyptus grandis Hill. com e sem a influência de corredores ecológicos, bem como verificar a viabilidade de construção de um ramal de serviço paralelo à vegetação nativa existente. Na análise técnica foi determinada a eficiência operacional, a disponibilidade mecânica e a produtividade da máquina. Na análise de viabilidade financeira foram determinados os custos da garra no processamento da madeira em dois projetos (com e sem a existência de corredor ecológico) e de construção de um ramal de serviço paralelo ao lado do talhão com a presença de vegetação nativa. A garra traçadora apresentou alta disponibilidade mecânica e eficiência operacional nos dois projetos avaliados. Os principais fatores influentes na duração de seu ciclo operacional e na sua produtividade foram o volume médio por árvore e a altura média das pilhas de madeira. A produtividade efetiva desta máquina foi maior no projeto PG1 (desprovido de corredores ecológicos) por apresentar um maior perímetro linear para a distribuição das pilhas de madeira e, consequentemente, menores alturas destas. A construção de um ramal de serviço paralelo ao corredor ecológico mostrou-se viável financeiramente.
\end{abstract}

Palavras-chave: colheita mecanizada, processamento de árvores, rendimento operacional

\begin{abstract}
This study aims to analyze the operational performance of the grapple saw in Eucalyptus grandis Hill stands with and without the influence of ecological corridors, as well as to verify the feasibility of building a service branch for the grapple saw parallel to existing native vegetation. In the technical analysis, the operational efficiency, mechanical availability, and productivity of the machine were determined. In the financial viability analysis, the costs of the grapple saw in wood processing were determined by application in two projects (with and without the presence of an ecological corridor) and with the construction of a parallel service branch next to the native vegetation. The grapple saw showed high mechanical availability and operational efficiency in the two evaluated projects. The main factors that influence the duration of its operational cycle and productivity were the average volume per tree and average height of the wooden cuttings. The effective productivity of this machine was higher in the PG1 project (devoid of ecological corridors) because it has a larger linear perimeter for the distribution of wooden piles and consequently, their lower heights. The construction of a service branch parallel to the ecological corridor proved to be financially viable.
\end{abstract}

Keywords: mechanized harvesting, tree processing, operational yield

Fonte de financiamento: Nada a declarar.

Conflito de interesse: Nada a declarar.

Autor correspondente: luizzaraujo@hotmail.com

Recebido: 30 novembro 2020

Aceito: 30 março 2021.

Editor: Paulo Henrique Müller Silva.

(c) Este é um artigo publicado em acesso aberto (Open Access) sob a licença Creative Commons Attribution, que permite uso, distribuição e By reprodução em qualquer meio, sem restrições desde que o trabalho original seja corretamente citado. 


\section{INTRODUÇÃO}

A colheita florestal é uma das etapas mais importantes e complexas do processo de produção da madeira dada as interações de inúmeras variáveis de natureza técnica, econômica, operacional e ambiental, com grande impacto no custo da madeira posto-fábrica.

Segundo Indústria Brasileira de Árvores (2020) a indústria brasileira de árvores plantadas é, atualmente, uma referência mundial por sua atuação pautada na sustentabilidade, indo além dos requisitos legais.

Uma estratégia que tem trazido importantes benefícios para o equilíbrio ambiental e contribuído para a preservação e conservação dos recursos naturais (sustentabilidade) são as faixas de vegetação nativa ou plantada, denominados de corredores ecológicos junto aos povoamentos florestais. Interligados entre si e às áreas de reserva e preservação permanente, dão ao projeto florestal a forma de uma malha (mosaico), permitindo maior fluxo gênico entre as áreas de proteção.

Segundo Moreira \& Rodriguez (2010), o estabelecimento de corredores de conectividade entre fragmentos separados constitui-se em uma importante estratégia para permitir o aumento da população viável e conservar ambientes naturais. Seoane et al. (2010) acrescentam que corredores ecológicos são a alternativa mais viável, se não a única, para a desfragmentação florestal.

Entretanto, apesar de sua grande importância ambiental, os corredores ecológicos podem causar efeitos negativos no desempenho operacional das máquinas de colheita florestal e, consequentemente, nos custos de produção. Pois, a presença destes "elementos de paisagem" torna-se obstáculo para a movimentação de máquinas e equipamentos, além de limitar os locais de empilhamento e as saídas da madeira, causando alterações significativas no planejamento da atividade.

Segundo Santos et al. (2016), a colheita florestal é a etapa do processo que gera maior impacto no custo de produção, compreendendo as fases de corte, extração, processamento e carregamento da madeira nos veículos de transporte. Neste sentido, visando aumentar a produtividade e, consequentemente, reduzir custos de produção, sempre que possível, esta atividade deve ser realizada de forma mecanizada. Além destes benefícios, a mecanização da colheita florestal resulta em melhorias ergonômicas e de segurança no trabalho (Diniz et al., 2018).

Para Simões \& Fenner (2010), a realização de estudos sobre as variáveis que influenciam a produtividade de máquinas de colheita de madeira tornou-se imperativo, visando à minimização dos custos e a otimização operacional. Como muitas dessas variáveis não são consideradas, dada a difícil mensuração, a determinação de cada uma delas contribuirá para a consolidação de um planejamento mais eficiente, com reflexo na gestão econômica das empresas.

Apesar da busca contínua pela redução de custos da colheita florestal, existe, atualmente, uma preocupação crescente das empresas quanto à maneira mais adequada de realizar essa atividade, investigando novas alternativas mitigadoras dos impactos ambientais negativos. Isto ocorre devido às exigências da legislação brasileira e de órgãos certificadores nacionais e internacionais, somados ao aumento da consciência ambiental adquirida ao longo dos últimos anos (Oliveira de Paula, 2011).

As influências de obstáculos naturais sobre a produtividade de máquinas florestais são ainda pouco conhecidas e estudadas. Neste sentido, o escopo deste estudo visou avaliar as consequências de corredores ecológicos no desempenho operacional de uma garra traçadora, responsável pelo processamento de madeira às margens do talhão. Como a vegetação nativa referente aos corredores não pode ser afetada, objetivou-se ainda avaliar a viabilidade financeira da construção de um ramal de serviço paralelamente aos corredores ecológicos.

A hipótese estabelecida para o desenvolvimento da pesquisa é de que a construção de um ramal de serviço provisório paralelamente ao corredor ecológico é interessante 
financeiramente, devido ao aumento de produtividade da garra traçadora compensar os custos desta infraestrutura.

\section{MATERIAL E MÉTODOS}

\section{Local de estudo}

A pesquisa foi desenvolvida em plantios clonais de Eucalyptus grandis Hill., pertencentes a uma empresa florestal localizada na região central de Minas Gerais, nos municípios de

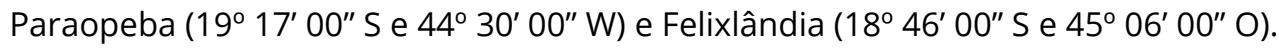

De acordo com a classificação de Köppen os municípios avaliados apresentam clima do tipo AW (Martins et al., 2018). O município de Paraopeba apresenta acumulado anual médio de chuvas de $1.070 \mathrm{~mm}$ e temperatura média anual de $23,0^{\circ} \mathrm{C}$. Felixlândia possui temperatura média anual de $20,4^{\circ} \mathrm{C}$ e precipitação média anual acumulada de $1.235 \mathrm{~mm}$.

O relevo é caracterizado como plano a suave ondulado com inclinação máxima de até $5 \%$, altitudes variando de 731 a $748 \mathrm{~m}$. Os povoamentos avaliados nas duas regiões tinham idade entre oito e onze anos, altura média das árvores de 31 metros, diâmetro médio a 1,30 m do solo (DAP) variando entre 14,70 e $20,50 \mathrm{~cm}$, espaçamento de $3 \mathrm{~m} \times 3 \mathrm{~m}$ com aproximadamente 1058 indivíduos por hectare.

\section{Condições de trabalho}

Avaliou-se a produtividade da garra traçadora em duas condições: 1 - talhões desprovidos de corredores ecológicos (com possibilidade de processamento e empilhamento de madeira em seus quatro lados), denominado de Projeto PG1, e, 2 - talhões com influência de corredores ecológicos (com impossibilidade de processamento e empilhamento em pelo menos um de seus lados), denominado de Projeto PG2.

Os dados técnicos que representam as duas situações de trabalho são mostrados na Tabela 1.

Tabela 1. Dados técnicos (médios) referentes aos projetos avaliados

\begin{tabular}{ccc} 
Dados & \multicolumn{2}{c}{ Projeto } \\
\cline { 2 - 3 } & PG1 & PG2 \\
\hline Espécie & E. grandis & E. grandis \\
Espaçamento $(\mathrm{m})$ & $3,00 \times 3,00$ & $3,00 \times 3,00$ \\
Idade (anos) & 9,2 & 11,0 \\
No de árvores por ha & 1080 & 1036 \\
DAP médio $(\mathrm{cm})$ & 17,5 & 20,0 \\
Altura média $(\mathrm{m})$ & 30,79 & 32,6 \\
Volume médio por árvore $\left(\mathrm{m}^{3}\right)$ & 0,38 & 0,51
\end{tabular}

DAP = Diâmetro a altura do peito

\section{Sistema de colheita}

A finalidade da madeira produzida pela empresa é a produção de carvão vegetal. Neste sentido, o sistema de colheita adotado e avaliado foi o de árvores inteiras (full-tree), com corte e derrubada das árvores no interior do talhão realizado pelo conjunto mecânico Feller buncher. A extração dos feixes até à margem da estrada foi executada pelo Skidder, sendo o traçamento ou processamento dos fustes realizados às margens do carreador, com auxílio de uma escavadora hidráulica equipada com cabeçote traçador, denominada de garra traçadora. 


\section{Descrição técnica da garra traçadora}

A máquina base equipada com a garra traçadora correspondeu a uma escavadora de acionamento hidráulico de esteiras, marca Carterpillar, modelo 320D FM configuração florestal, composta de um motor Caterpillar C6.6 com ACERT ${ }^{\mathrm{TM}}$ de 6 cilindros, potência nominal de $157 \mathrm{HP}$ e, peso operacional aproximado de $20.660 \mathrm{~kg}$. A garra de traçamento adaptada a máquina base é da marca J de Souza modelo TJP - GJ 580rt, com área útil de $0,58 \mathrm{~m}^{2}$, sabre único de 45", motor de $80 \mathrm{cc}$, corrente $3 / 4$ " e peso de $940 \mathrm{Kg}$.

\section{Ciclo operacional}

As operações efetivas englobaram todos os movimentos planejados que ocorreram repetitivamente durante o decurso do trabalho da máquina e, que, resultaram em produção e, ou, foram necessárias para a realização da atividade. Avaliaram-se também as interrupções operacionais e mecânicas da máquina (Tabela 2).

Tabela 2. Descrição do ciclo operacional da garra traçadora

\begin{tabular}{|c|c|}
\hline Operações & Descrição \\
\hline Agrupar feixe & $\begin{array}{l}\text { Tempo para acumular os fustes na garra e os organizar no local } \\
\text { estabelecido para processamento e empilhamento }\end{array}$ \\
\hline Medir feixe & $\begin{array}{l}\text { Tempo para arrumar e medir os feixes na bitola estabelecida para } \\
\text { processamento ( } 5 \text { metros } \pm 10 \mathrm{~cm} \text { ), mediante gabarito fixado na garra }\end{array}$ \\
\hline Traçar feixe & Tempo para seccionar, em toretes, o feixe acumulado na garra \\
\hline Arrumar pilha & $\begin{array}{c}\text { Tempo para depositar os toretes traçados de forma organizada e } \\
\text { uniforme sobre a pilha de madeira processada }\end{array}$ \\
\hline Interrupções operacionais & $\begin{array}{l}\text { Tempo com paradas repetidas ou casuais durante o decurso do } \\
\text { trabalho, causando interrupção temporária do ciclo operacional }\end{array}$ \\
\hline Interrupções mecânicas & Tempo para abastecimento ou realização de reparos (manutenção) \\
\hline
\end{tabular}

\section{Análise técnica e operacional da garra traçadora}

Consistiu na determinação da eficiência operacional, disponibilidade mecânica e da produtividade efetiva da garra traçadora em talhões com e sem a presença de corredores ecológicos. As análises foram realizadas com base nos dados obtidos por intermédio do Estudo de Tempos e Movimentos (ETM). A coleta dos dados foi efetuada pelo método de cronometragem de tempo contínuo (Simões et al, 2014) com utilização de cronômetros centesimais e planilhas específicas.

O número mínimo de ciclos operacionais coletados durante o ETM foi estabelecido com base na metodologia proposta por Barnes (1977). Para tal, realizou-se um estudo piloto com a coleta de 10 ciclos operacionais e, a partir desta amostra estabeleceu-se o número mínimo de medições, para um erro de amostragem fixado em $5 \%$, a $95 \%$ de probabilidade, por meio da Equação 1 proposta por Conaw (1977):

$n \geq \frac{t^{2} x C V^{2}}{E^{2}}$

Em que: $\mathrm{n}$ = número mínimo de ciclos necessários, $\mathrm{t}=$ valor de $\mathrm{t}$, para o nível de probabilidade desejado a (n-1) graus de liberdade, CV = coeficiente de variação (\%), e E = erro admissível (\%).

Para evitar eventuais distorções nos resultados da atividade de traçamento da madeira escolheu-se um operador experiente, sendo este mantido durante todo período de coleta de dados. 


\section{Disponibilidade mecânica}

Foi obtida por intermédio da relação entre o tempo de trabalho total destinado para a realização das operações (tempo em que a máquina se encontrou apta para o desempenho de suas funções) e o período em que a mesma interrompeu o trabalho (por encontrar-se em manutenção para abastecimento ou realização de reparos). A disponibilidade mecânica foi obtida conforme Equação 2:

$$
D M=\frac{H T-H M}{H T} \times 100
$$

Em que: $\mathrm{DM}=$ disponibilidade mecânica (\%), $\mathrm{HT}=$ tempo total de trabalho (horas), $\mathrm{HM}=$ tempo de manutenção (horas).

\section{Eficiência operacional}

Foi obtida da relação entre o tempo de trabalho efetivo e o período em que a máquina interrompeu o trabalho por paradas eventuais (interrupções operacionais). Sendo expressa pela Equação 3:

$$
E O p=\frac{T e f}{T e f+H i} x 100
$$

Em que: EOp = eficiência operacional (\%), Tef = tempo de trabalho efetivo (horas), $\mathrm{Hi}=$ tempo de interrupções operacionais (horas).

\section{Produtividade efetiva}

Foi determinada da relação entre volume de madeira processada e tempo efetivo de trabalho, conforme Equação 4).

$$
P e f=\frac{\sum V o l}{\sum T e f}
$$

Em que: Pef = produtividade efetiva $\left(m^{3} h^{-1}\right)$, Vol = volume, em metros cúbicos de madeira com casca processada $\left(\mathrm{m}^{3}\right)$, Tef $=$ tempo efetivo de trabalho (horas).

\section{Altura média de pilha}

Obteve-se esta variável por meio de uma trena convencional, medindo-se a altura a cada dois metros de deslocamento linear ao longo da pilha de madeira processada e confeccionada pela garra traçadora. Ao final da medição foi calculada a média aritmética simples dos valores obtidos.

\section{Analise estatistica}

Consistiu na análise de regressão utilizando o software R Development Core Team (2018), de modo a verificar a relação entre a variável dependente (produtividade) e as variáveis independentes (fatores do povoamento: volume médio por árvore, diâmetro, altura, e altura média da pilha de madeira).

Utilizou-se como critérios de seleção da melhor equação estimada: a significância dos parâmetros, maior coeficiente de determinação $\left(R^{2}\right)$, seguida pelo menor número de variáveis independentes associadas. As variáveis testadas que não apresentaram significância estatística foram descartadas do modelo. 


\section{Avaliação de produtividade}

Após o ajuste e seleção da melhor equação avaliou-se a produtividade na etapa de processamento da madeira, com base na influência das variáveis independentes consideradas no modelo.

\section{Análise de custos referente a construção de um ramal para empilhamento de madeira}

O intuito desta etapa foi verificar se os custos extras inerentes a construção dessa infraestrutura entre o plantio de eucalipto e os corredores ecológicos seriam compensados pela redução de custos da garra traçadora, ocasionado pelo aumento de sua produtividade ao se poder distribuir a madeira nos quatro lados do talhão. Os ramais de serviço caracterizam-se pelo seu aspecto temporário, sendo confeccionados apenas na época da colheita florestal, não acarretando perda de área útil, uma vez que os mesmos são replantados após a retirada da madeira.

Para esta análise foi selecionado um talhão (pertencente ao projeto PG2) com presença de corredor de vegetação nativa em seu interior (Figura 1a), denominado de TN3 (talhão com três lados disponíveis para arraste e empilhamento de madeira). A Figura $1 \mathrm{~b}$ refere-se a proposta de construção de um ramal de serviço entre a faixa de vegetação nativa e a área plantada no talhão TN3, que foi denominado como TN4, ou seja, talhão com quatro lados disponíveis para arraste e empilhamento de madeira.

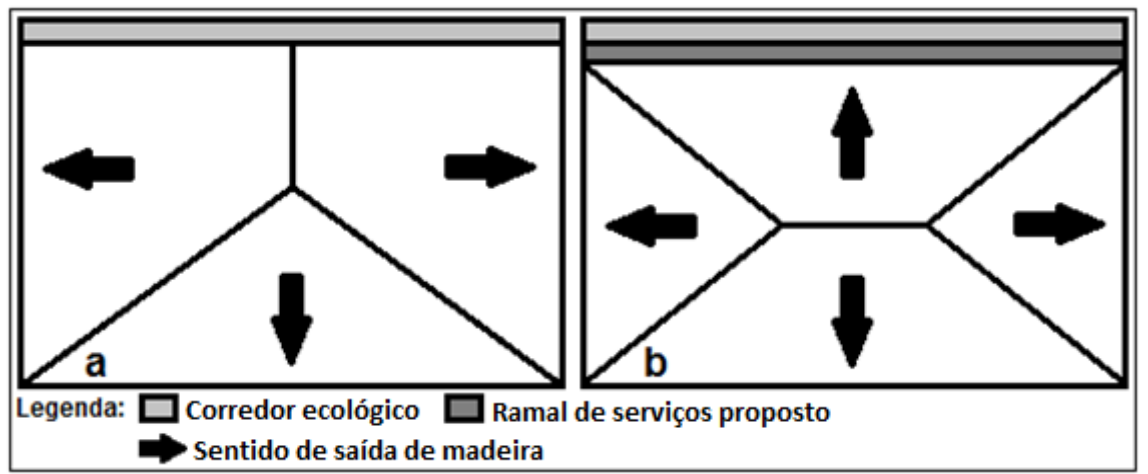

Figura 1. Representação esquemática dos talhões com a quantidade de lados e direções em que se pode arrastar e empilhar a madeira: a -TN3: talhão avaliado (situação real), b -TN4: talhão proposto (situação simulada).

A Tabela 3 apresenta as características dos talhões TN3 e TN4 com base em dados reais coletados em campo. Ressalta-se que, para TN4, utilizou-se a AMP (Altura Média de Pilha) calculada para os talhões sem influência de corredores ecológicos.

Tabela 3. Características dos talhões (TN3 - Avaliado, TN4 - Proposto)

\begin{tabular}{ccc} 
Características & \multicolumn{2}{c}{ Talhões } \\
\cline { 2 - 3 } & TN3 & TN4 \\
Dimensões & $600 \times 480$ & $600 \times 480$ \\
Área (ha) & 28,80 & 28,80 \\
Número de saídas do talhão & 3 & 4 \\
Perímetro útil para deposição de madeira $(\mathrm{m})$ & 1560,0 & 2160,0 \\
Espaçamento $(\mathrm{m})$ & $3,00 \times 3,00$ & $3,00 \times 3,00$ \\
Volume médio por árvore $\left(\mathrm{m}^{3}\right)$ & 937 & 937 \\
Volume $\left(\mathrm{m}^{3}\right.$ ha $\left.^{-1}\right)$ & 0,39 & 0,39 \\
Volume total $\left(\mathrm{m}^{3}\right)$ & 372,85 & 372,85 \\
& 10738,08 & 10738,08
\end{tabular}


A partir da equação de regressão ajustada estimou-se, para cada talhão, o rendimento operacional da garra traçadora, em metros cúbicos por hora efetiva de trabalho. Com base nesta informação determinou-se o total de horas trabalhadas (HTT) para processar toda a madeira contida em cada talhão, dividindo-se o volume total de madeira $\left(\mathrm{m}^{3}\right)$ pela produtividade efetiva $\left(\mathrm{m}^{3}\right.$ hora $\left.{ }^{-1}\right)$ da garra traçadora.

Em seguida determinou-se o custo de construção de um ramal de serviço $\left(R \$ \mathrm{~m}^{-2}\right)$ com dimensões de 600 metros de comprimento (equivalente à extensão do corredor ecológico) e largura de 8 metros (proporcional a um carreador florestal padrão), totalizando uma área de 4.800 metros quadrados.

Os dados referentes ao custo de construção do ramal de serviços $\left(R \$ \mathrm{~m}^{-2}\right)$ e o valor de locação da garra traçadora ( $R \$$ hora $^{-1}$ ) basearam-se em informações de prestadores de serviços da região de estudo.

\section{RESULTADOS E DISCUSSÃO}

\section{Análise técnica e operacional da garra traçadora}

No estudo foram coletados 43 e 66 ciclos operacionais para os projetos PG1 e PG2, respectivamente. A Figura 2 apresenta os tempos percentuais gastos nas etapas do ciclo operacional da máquina.
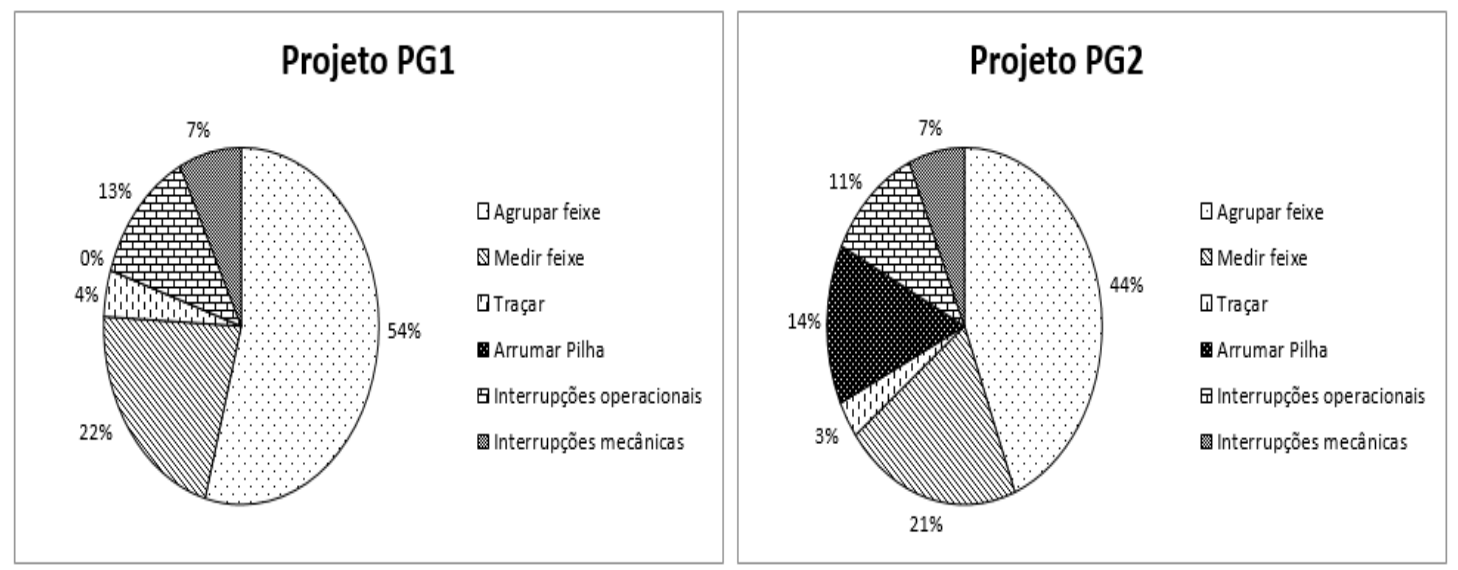

Figura 2. Distribuição percentual dos tempos médios gastos na realização das etapas parciais do ciclo operacional da garra traçadora

A etapa "Agrupar feixe" representou o maior tempo gasto no ciclo operacional da garra traçadora, com percentuais de $54 \%$ e $44 \%$ do tempo total para os projetos PG1 e PG2, respectivamente. Isto se deve ao elevado grau de dificuldade na realização desta operação que exige grande habilidade e precisão do operador para apanhar o feixe de madeira, nivelar (encabeçar) os fustes na extremidade a ser traçada e, posicionar os toretes no local adequado de empilhamento, garantindo posteriormente qualidade na confecção da pilha processada na margem da estrada. Este resultado corrobora com o obtido por Fiedler et al. (2008) em que, o elemento parcial do ciclo operacional da garra traçadora que consumiu o maior tempo foi o de recolhimento e organização dos feixes de árvores.

O segundo maior tempo gasto foi referente a etapa "Medir feixe", representando percentuais de $22 \%$ no projeto PG1 e $21 \%$ no PG2. Isto se explica devido a ampla atenção e destreza exigidas do operador durante a medição do tamanho dos toretes a serem traçados, de acordo com um gabarito referencial afixado no cabeçote traçador da máquina. $O$ tamanho exigido pela empresa era de 5 metros com limite de aceite de $\pm 10 \mathrm{~cm}$.

A etapa "Traçar" consumiu menor tempo de execução em ambas os projetos (PG1 e PG2), sendo influenciada diretamente pela perda de afiação da corrente do conjunto de corte do cabeçote traçador. 
A principal diferença observada entre as duas condições avaliadas refere-se a etapa "Arrumar pilha" a qual não ocorreu no projeto PG1 e, no projeto PG2, representou $14 \%$ do tempo total do ciclo operacional. A justificativa para esta operação ter ocorrido apenas no projeto PG2 deve-se a maior altura média de pilha, pois a presença de corredor ecológico limita a área útil de deposição da madeira arrastada pelo skidder. Essa situação ocasiona maior acúmulo de madeira nas bordas do talhão, exigindo maior tempo na confecção e arranjo de pilhas mais altas.

As "Interrupções mecânicas" foram responsáveis por 7\% do tempo total gasto para realização do ciclo operacional, em ambos os projetos. As principais "Interrupções mecânicas" observadas durante o decurso do trabalho da garra traçadora foram: as paradas para manutenção preventiva diária e, para substituição e recolocação da corrente, quando a mesma perdia afiação ou se soltava do conjunto de corte.

As interrupções operacionais (hidratação do operador, uso do rádio comunicador, entre outras) representaram $13 \%$ e $11 \%$ do tempo do ciclo operacional, nos projetos PG1 e PG2, respectivamente.

A Figura 3 ilustra a constituição dos tempos médios do ciclo operacional de processamento com a garra traçadora, expressa em segundos. O ciclo operacional médio de trabalho efetivo com a garra traçadora foi de 138,50 e 172,43 segundos para os projetos PG1 e $P G 2$, respectivamente.
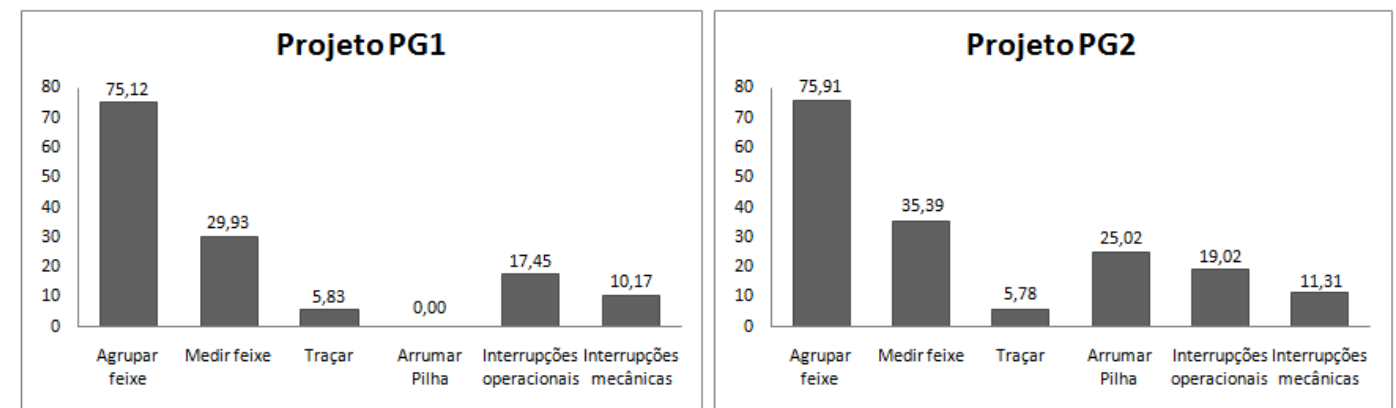

Figura 3. Distribuição dos tempos gastos nas atividades parciais e interrupções do ciclo operacional da garra traçadora, em segundos

A etapa "Agrupar feixe" não sofreu influência da presença ou ausência do corredor ecológico, mostrando similaridade nos tempos para as duas condições avaliadas.

Na etapa "Medir feixe" detectou-se diferença nos tempos de sua execução, no qual o projeto PG2 foi superior ao projeto PG1. Uma justificativa para isso deve-se à exigência de maior potência do sistema hidráulico para movimentar e posicionar feixes de maior dimensão (diâmetros e pesos), requerendo do operador maior cuidado e atenção na realização dessa operação (projeto PG2). Assim, para este elemento, em cada ciclo operacional executado no projeto PG2, gastou-se em média cinco segundos a mais em relação ao projeto PG1.

A etapa relacionada ao processo de "Traçar madeira" também não foi influenciada pelas características dos projetos analisados, uma vez que os tempos gastos na realização desta etapa foram semelhantes, em ambas as condições.

A operação de "Arrumar pilha", que não ocorreu no projeto PG1, demandou um tempo médio de 25,02 segundos no projeto PG2. Este adicional de tempo foi convertido em valores operacionais da garra traçadora, sendo confrontado com os custos referentes a construção do ramal de serviço para empilhamento da madeira paralelo ao corredor ecológico.

Os tempos de interrupções operacionais e mecânicas foram ligeiramente maiores no projeto PG2 em relação ao PG1. Com base nos tempos médios dos ciclos, a eficiência operacional média da garra traçadora foi de $85,3 \%$ e, a disponibilidade mecânica de $90,8 \%$ no projeto PG1. No projeto PG2 estas foram de $87,3 \%$ e $92,0 \%$, respectivamente.

A altura média de pilha obtida no projeto PG1 foi de 1,35 metros e 2,31 metros no Projeto PG2. 
Portanto, em função das diferenças nas condições de cada projeto avaliado, a produtividade da garra traçadora foi de 72,29 metros cúbicos de madeira processada por hora efetiva ( $\mathrm{m}^{3}$ hora $^{-1}$ ) no projeto PG1 e, no projeto PG2, de 49,51 $\mathrm{m}^{3}$ hora-1 . Lopes et al. (2008) estudando a garra traçadora encontrou resultados semelhantes ao desta pesquisa, na qual essa máquina produziu em média, 50,16, 64,87 e 76,55 $\mathrm{m}^{3}$ hora-1 para os níveis de produtividade do povoamento de 100, 200 e $300 \mathrm{~m}^{3} \mathrm{ha}^{-1}$, respectivamente.

\section{Análise estatística}

Com base nas variáveis independentes mensuradas no estudo da garra traçadora: "volume médio por árvore" (VMA) e "altura média de pilha" (AMP) ajustou-se uma equação de regressão para estimar a produtividade da referida máquina (Equação 1).

$$
Y=113,36-45,8 V M A^{* *}-17,53 A M P^{* *} \quad\left(R^{2}=0,83\right)
$$

Onde: $\mathrm{Y}=$ Produtividade da garra traçadora $\left(\mathrm{m}^{3}\right.$ hora-1 $)$, VMA: volume médio por árvore $\left(\mathrm{m}^{3}\right)$, AMP: altura média de pilha $(\mathrm{m})$.

Com base no coeficiente de determinação verificou-se que as variáveis VMA e AMP juntas, explicaram 83\% da variação na produtividade da garra traçadora.

Constatou-se a partir da equação de regressão estimada que, as relações de proporcionalidade entre a variável dependente e as independentes se comportam em sentido inverso, ou seja, quanto maiores os valores de VMA e AMP, menor foi a produtividade da garra traçadora.

Isso ocorre devido à maior dificuldade do operador em efetuar a etapa "Medir feixe" em pilhas com maiores VMA e peso, as quais exigirão também o uso de maior potência da máquina e, consequentemente, maiores tempos na execução desta operação.

Simões et al. (2014) afirmaram que, dentre outros, o fator de maior influência sobre a produtividade da garra traçadora é o volume médio individual das árvores. Por sua vez, Schettino et al. (2015) detectaram baixa sensibilidade da garra traçadora em relação à produtividade da floresta e, apesar dos resultados terem gerado uma correlação positiva, essa não foi significativa.

Quanto a AMP, o maior tempo gasto para confeccionar e organizar pilhas mais altas em talhões com presença de corredores ecológicos provocou redução da produtividade da máquina.

\section{Avaliação de produtividade}

Para esta análise foram definidos intervalos regulares de Volume médio por árvore (VMA) e Altura média de pilha (AMP), com base na amplitude dos dados coletados em campo.

As Tabelas 4 e 5 mostram separadamente, as perdas de produtividade da garra traçadora decorrente da variável VMA e AMP, respectivamente.

Tabela 4. Estimativa de produtividade da garra traçadora com variação do VMA (X1)

\begin{tabular}{|c|c|c|c|}
\hline Variável X1 & Variável X2 & Variável Y & \\
\hline $\begin{array}{c}\text { Volume médio por } \\
\text { árvore }\left(\mathrm{m}^{3}\right)\end{array}$ & $\begin{array}{c}\text { Altura média por } \\
\text { pilha }(\mathrm{m})\end{array}$ & $\begin{array}{c}\text { Produtividade }\left(\mathrm{m}^{3}\right. \\
\left.\text { hora }^{-1}\right)\end{array}$ & Produtividade (\%) \\
\hline 0,2 & 2,0 & 69,14 & - \\
\hline 0,3 & 2,0 & 64,55 & 6,63 \\
\hline 0,4 & 2,0 & 59,97 & 13,27 \\
\hline 0,5 & 2,0 & 55,38 & 19,90 \\
\hline
\end{tabular}


O aumento do "volume médio por árvore" causou redução de até 19,90\% na produtividade da garra traçadora.

Tabela 5. Estimativa de produtividade da garra traçadora com variação da AMP (X2)

\begin{tabular}{|c|c|c|c|}
\hline Variável X1 & Variável X2 & Variável Y & \\
\hline $\begin{array}{l}\text { Volume médio por } \\
\text { árvore }\left(\mathrm{m}^{3}\right)\end{array}$ & $\begin{array}{l}\text { Altura média por } \\
\text { pilha }(\mathrm{m})\end{array}$ & $\begin{array}{c}\text { Produtividade } \\
\left(\mathrm{m}^{3} \mathrm{hora}^{-1}\right)\end{array}$ & Produtividade (\%) \\
\hline 0,4 & 1,0 & 77,49 & - \\
\hline 0,4 & 1,5 & 68,73 & 11,31 \\
\hline 0,4 & 2,0 & 59,97 & 22,62 \\
\hline 0,4 & 2,5 & 51,20 & 33,93 \\
\hline 0,4 & 3,0 & 42,44 & 45,24 \\
\hline
\end{tabular}

A influência da variável "altura média de pilha" seguiu a mesma tendência do VMA. Porém, neste caso, as perdas de produtividade da garra traçadora foram ainda mais expressivas, representando 45,24\% de redução comparativamente à melhor condição.

Estes resultados são importantes porque permitem os gestores florestais tomarem melhores decisões operacionais, tais como: determinar o número ideal de máquinas para processar madeira em um talhão com alto VMA, ou ainda, avaliar a necessidade de construção de um ramal de serviço em talhões com influência de corredores ecológicos, devido à maior AMP.

Verificou-se ainda que a diminuição da altura média de pilha até o valor mínimo de um metro ocasiona aumento de produtividade da garra traçadora. Porém abaixo desta medida a AMP pode causar redução de produtividade da máquina, devido ao maior comprimento / extensão das pilhas de fustes formadas pelo Skidder, exigindo maior deslocamento da garra no processamento da madeira.

\section{Análise de viabilidade de construção de um ramal para empilhamento de madeira}

A construção de ramais de serviço em talhões com a presença de corredor ecológico possibilita que o número de saídas de madeira e o perímetro útil para empilhamento de feixes sejam semelhantes a talhões sem a existência dessa faixa de vegetação. Assim, a construção dessa infraestrutura ao lado do corredor ecológico permite uma distribuição uniforme dos feixes de madeira em todo perímetro do talhão (em seus quatro lados), facilitando o trabalho da garra traçadora e, consequentemente, resultando em maior rendimento operacional desta máquina.

O VMA observado no talhão TN3 e TN4 foi de 0,39 $\mathrm{m}^{3}$, uma vez que se tratam de um mesmo talhão. A AMP calculada para o talhão TN3 foi de 2,20 m. Ressalta-se que, para TN4, utilizou-se a AMP de 1,35 m (calculada para os talhões sem influência de corredores ecológicos).

As Tabelas 6 e 7 apresentam os custos de construção do ramal de serviço proposto, bem como os custos de processamento da madeira para os dois talhões avaliados, respectivamente. O custo de construção do ramal de serviços englobou o corte das árvores $(32,77 \%)$, destoca ou retirada de tocos (23,96\%), limpeza e terraplanagem do local (18,22\%) e custo de replantio após o uso da área $(25,05 \%)$.

Tabela 6. Custos de construção do ramal de serviços

\begin{tabular}{cccc}
\hline Dimensões $(\mathbf{m})$ & Área $\left(\mathbf{m}^{\mathbf{2}}\right)$ & Custo $\left(\mathbf{R} \mathbf{\$} \mathbf{~ m}^{-2}\right)$ & Custo total $(\mathbf{R} \mathbf{})$ \\
\hline $600,0 \times 8,0$ & $4.800,00$ & 1,01 & $4.848,00$
\end{tabular}


Tabela 7. Custos de processamento da madeira para o talhão TN3 e TN4

\begin{tabular}{cccccc}
\hline Talhão & $\begin{array}{c}\text { Prod. } \\
\left(\mathbf{m}^{\mathbf{3}} \text { hora }^{-1}\right)\end{array}$ & $\begin{array}{c}\text { Vol. Talhão } \\
\left(\mathbf{m}^{\mathbf{3}} \mathbf{)}\right.\end{array}$ & HTT & $\begin{array}{c}\text { Custo } \\
\text { (R\$/hora) }\end{array}$ & $\begin{array}{c}\text { Custo por } \\
\text { máquina (R\$) }\end{array}$ \\
\hline TN3 & 56,91 & $10.738,08$ & 188,69 & 300,00 & $56.606,98$ \\
TN4 & 71,81 & $10.738,08$ & 149,54 & 300,00 & $44.860,94$ \\
\hline
\end{tabular}

Prod.: produtividade, Vol.: Volume, HTT: horas totais trabalhadas

O total de horas trabalhadas pela garra traçadora no talhão sem o corredor ecológico foi de $149 \mathrm{~h}$ e $32 \mathrm{~min}$, enquanto que no talhão com presença da faixa ecológica foi de $188 \mathrm{~h}$ e $41 \mathrm{~min}$.

Com a implantação do ramal de serviços obteve-se uma diminuição de 39h:09':00" no tempo de trabalho da garra traçadora no talhão TN4 em comparação ao TN3, correspondendo a uma redução de 20,75\% no tempo de processamento da madeira. Esse aumento de produtividade da garra traçadora decorrente da construção do ramal de serviços representou uma redução de custo de processamento da madeira de todo o talhão proposto (28,80 hectares), na ordem de $\mathrm{R} \$ 11.746,04$. Como o custo do ramal de serviços no referido talhão correspondeu a $\mathrm{R} \$ 4.848,00$, isto gerou um saldo positivo de $\mathrm{R} \$ 6.898,04$, equivalente a $\mathrm{R} \$ 239,52$ por hectare, mostrando ser vantajoso e viável a construção desta infraestrutura paralela à vegetação existente (corredor ecológico).

A construção do ramal de serviço em talhões com presença de corredor ecológico pode gerar ainda outros benefícios como uma redução de tempo e custo nas atividades de corte florestal e extração da madeira. Entretanto, essas análises não constituíram objeto deste estudo.

\section{CONCLUSÕES}

A garra traçadora apresentou alta disponibilidade mecânica e eficiência operacional nos dois projetos avaliados, sendo os principais fatores influentes na duração de seu ciclo operacional e na sua produtividade o volume médio por árvore e a altura média das pilhas de madeira.

A produtividade efetiva desta máquina foi maior no projeto PG1 (desprovido de corredores ecológicos) por apresentar um maior perímetro linear para a distribuição das pilhas de madeira e, consequentemente, menores alturas destas.

A construção de um ramal de serviço paralelo à vegetação nativa/corredor ecológico existente mostrou-se viável financeiramente.

\section{REFERÊNCIAS BIBLIOGRÁFICAS}

Barnes, R. M. (1977). Estudos de movimentos e de tempos: projeto e medida do trabalho (6. ed., 635 p.). São Paulo: Edgard Blucher.

Conaw, P. L. (1977). Estatística (246 p.). São Paulo: Edgard Blucher.

Diniz, C. C. C., Robert, R. C. G., \& Vargas, M. B. (2018). Avaliação técnica de cabeçotes individual e múltiplo no processamento de madeira. Advances in Forestry Science, 5(1), 253-258. http://dx.doi.org/10.34062/afs.v5i1.5523.

Fiedler, N. C., Rocha, E. B., Lopes, E., \& Da, S. (2008). Análise da produtividade de um sistema de colheita de árvores inteiras no norte do estado de Goiás. Floresta, 38(4), 577-586. http://dx.doi.org/10.5380/rf.v38i4.13153.

Indústria Brasileira de Árvores - IBÁ. (2020). Anuário estatístico (66p.). Brasília: IBÁ.

Lopes, S. E., Fernandes, H. C., Santos, N. T., \& Rinaldi, P. C. N. (2008). Avaliação técnica e econômica de uma garra traçadora operando em diferentes produtividades. Scientia Forestalis, 36(79), 215-222.

Martins, F. B., Gonzaga, G., Santos, D. F., \& Reboita, M. S. (2018). Classificação climática de Köppen e de Thornthwaite para Minas Gerais: cenário atual e projeções futuras. Revista Brasileira de Climatologia, 14, 129-156. http://dx.doi.org/10.5380/abclima.v1i0.60896. 
Moreira, J. M. M. A. P., \& Rodriguez, L. C. E. (2010). A incorporação de corredores de conectividade no manejo de florestas industriais utilizando a heurística da RazãoR. Revista de Economia e Sociologia Rural, 48(2), 255-282. http://dx.doi.org/10.1590/S0103-20032010000200001.

R Development Core Team. (2018). R: a language and environment for statistical computing. Vienna: $\mathrm{R}$ Foundation for Statistical Computing.

Oliveira de Paula, E. N. S. (2011). Avaliação técnica, de custos e ambiental de dois modelos de harvester na colheita florestal (Tese de doutorado). Universidade Federal de Viçosa, Viçosa.

Santos, L. N., Fernandes, H. C., Silva, M. L. D. A., Teixeira, M. M., \& Souza, A. P. (2016). Avaliação de custos da operação de extração da madeira com forwarder. Cerne, 22(1), 27-34. http://dx.doi.org/10.1590/01047760201622012076.

Schettino, S., Minette, L. J., \& Souza, A. P. (2015). Correlação entre volumetria de florestas de eucalipto e produtividade e custos de máquinas de colheita de madeira. Revista Árvore, 39(5), 935-942. http://dx.doi.org/10.1590/0100-67622015000500016.

Seoane, C. E. S., Diaz, V. S., Santos, T. L., \& Froufe, L. C. M. (2010). Corredores ecológicos como ferramenta de desfragmentação de florestas tropicais. Pesquisa Florestal Brasileira, 30(63), 207-216. http://dx.doi.org/10.4336/30.63.207.

Simões, D., \& Fenner, P. T. (2010). Influência do relevo na produtividade e custos do harvester. Scientia Forestalis, 85(38), 107-114.

Simões, D., Fenner, P. T., \& Esperancini, M. S. T. (2014). Produtividade e custos do feller buncher e processador florestal em povoamento de eucalipto de primeiro corte. Ciência Florestal, 24(3), 621630. http://dx.doi.org/10.5902/1980509815742.

Contribuição dos Autores: LCA: conceituação, curadoria de dados, análise formal, investigação, metodologia, validação, visualização, escrita - primeira redação, escrita - revisão e edição, AMPL: conceituação, curadoria de dados, investigação, metodologia, administração do projeto, recursos, supervisão, escrita - primeira redação, escrita - revisão e edição, LCF: análise formal, visualização, escrita - revisão e edição, MLRO: análise formal, visualização, escrita - revisão e edição. 